\title{
Neural Changes in Control Implementation of a Continuous Task
}

\author{
Ovidiu V. Lungu, ${ }^{1,2}$ Meagan M. Binenstock, ${ }^{3}$ Megan A. Pline, ${ }^{3}$ Jennifer R. Yeaton, ${ }^{3}$ and James R. Carey ${ }^{3}$ \\ ${ }^{1}$ Brain Sciences Center, Veterans Affairs Medical Center, Minneapolis, Minnesota 55417, and Departments of ${ }^{2}$ Neuroscience and ${ }^{3}$ Physical Therapy, \\ University of Minnesota, Minneapolis, Minnesota 55455
}

\begin{abstract}
It is commonly agreed that control implementation, being a resource-consuming endeavor, is not exerted continuously or in simple tasks. However, most research in the field was done using tasks that varied the need for control on a trial-by-trial basis (e.g., Stroop, flanker) in a discrete manner. In this case, the anterior cingulate cortex (ACC) was found to monitor the need for control, whereas regions in the prefrontal cortex (PFC) were found to be involved in control implementation. Whether or not the same control mechanism would be used in continuous tasks was an open question. In our study, we found that in a continuous task, the same neural substrate subserves control monitoring (ACC) but that the neural substrate of control implementation changes over time. Early in the task, regions in the PFC were involved in control implementation, whereas later the control was taken over by subcortical structures, specifically the caudate. Our results suggest that humans possess a flexible control mechanism, with a specific structure dedicated to monitoring the need for control and with multiple structures involved in control implementation.
\end{abstract}

Key words: fMRI; cognitive control; ACC; DLPFC; caudate; adaptation

\section{Introduction}

Much research in cognitive control is focused on the recruitment of task-relevant resources in response to sudden changes in the environment (Garavan et al., 2002; Kerns et al., 2004b; Ridderinkhof et al., 2004). A prominent view of cognitive control is the response-conflict theory (Botvinick et al., 1999; Carter et al., 2000; MacDonald et al., 2000; Botvinick et al., 2001; Kerns et al., $2004 \mathrm{~b}$ ). This theory asserts that the amount of conflict between competing or concurrent cognitive processes is the basis of the modulatory signal used to recruit task-relevant resources. The theory also postulates that the control mechanism is based on two distinct components: (1) evaluative, located in the anterior cingulate cortex (ACC) that monitors conflict in the environment and signals the need for control; and (2) executive, located in the dorsolateral prefrontal cortex (DLPFC) that actually implements the control (Carter et al., 2000; Botvinick et al., 2004; Kerns et al., $2004 b$ ). Conflict situations are found in tasks that require overriding of prepotent responses, such as flanker or Stroop tasks (Botvinick et al., 1999; Kerns et al., 2004b), selecting actions from a set of equally permissible responses (Frith et al., 1991; Barch et al., 2000), or performing tasks prone to error commission (Braver et al., 2001; Menon et al., 2001). Most studies within conflict-adaptation paradigms have looked at control implemen-

Received Nov. 21, 2006; revised Jan. 9, 2007; accepted Feb. 5, 2007.

This work was supported by the National Institutes of Health (National Center for Research Resources Grant M01-RR00400 and Biomedical Technology Research Resources Grant P41-R008079) and Brain Sciences Chair, Department of Veterans Affairs, Veterans Affairs Medical Center (Minneapolis, MN).

Correspondence should be addressed to Dr. Ovidiu V. Lungu, Centre de Recherche de I'Institut Universitaire de Gériatrie de Montréal, Université de Montréal, Room M-6814, 4565 Chemin Queen Mary, Montreal, Quebec, Canada H3W 1W5. E-mail: Ovidiu.Lungu@criugm.rtss.qc.ca.

D0I:10.1523/JNEUROSC1.5051-06.2007

Copyright $\odot 2007$ Society for Neuroscience $\quad 0270-6474 / 07 / 273010-07 \$ 15.00 / 0$ tation during short-lasting discrete skills (Schmidt and Lee, 1999), such as reaction-time tasks, without addressing longerlasting continuous skills, such as tracking tasks. Indeed, Lee and Genovese (1989) found differential effects for motor skill acquisition for discrete versus continuous motor tasks. Thus, we questioned whether the same findings observed during discrete conflict tasks (Carter et al., 1998; Botvinick et al., 1999; Carter et al., 2000; MacDonald et al., 2000) would also be obtained when the conflict task was chronic and a continuous response was required. In the current study, we show that adaptation to chronic conflict is based on the same neural substrate that subserves short-lasting conflict trials (i.e., ACC and DLPFC) but only in the early stages of the task when performance is suboptimal; once the task is mastered, the control is implemented by basal ganglia.

\section{Materials and Methods}

Subjects. Twenty healthy subjects (11 females, 9 males), with a mean age of $25.1 \pm 3.8$ years, volunteered for this study. Inclusion criteria for participation included being right handed (Oldfield, 1971), having satisfactory vision or vision corrected with lenses, and having the full range of motion of the right index finger (metacarpophalangeal joint). Exclusion criteria included pregnancy, metals or implanted medical devices incompatible with magnetic resonance imaging (MRI), and claustrophobia. All subjects gave informed consent, and the study was approved by the local Institutional Review Board.

Tracking procedure. Subjects were positioned supine inside a 3 tesla magnet (Magnetom Trio; Siemens, Munich, Germany). The subjects' right hands were placed palm down comfortably on their lower abdomen using a foam wrist support to ensure that they had full index finger flexion and extension range of motion. Ear plugs and headphones were used to dampen the noise during the anatomical scan and to allow communication between the subject and the examiners. A mirror on the head coil allowed the subject to see the projection screen displaying the functional task. Functional MRI (fMRI)-compatible finger electrogoniom- 
eters with potentiometers (ETI Systems, Carlsbad, CA) were attached to the subject's right and left index fingers. The purpose of the left electrogoniometer was to verify that no motion occurred at the left index finger while tracking with the right. The voltage signal representing joint motion was directed to a computer (Dell Computer Company, Round Rock, TX) through an analog-to-digital converter that sampled the signal at 60 $\mathrm{Hz}$.

The subject's index finger range of motion in full flexion and extension was measured to individualize the amplitude of the target waveform to be tracked by each subject. The target waveform was a $0.4 \mathrm{~Hz}$ sine wave of variable amplitude. The uppermost peak of the wave was set at $85 \%$ of the subject's range of motion (with 100\% defined as full extension), and the lower peak of the wave was set at $15 \%$ of the subject's range of motion (with $0 \%$ defined as full flexion). Thus, the upper and lower peaks of the target were within each subject's range of motion. Subjects were instructed in tracking with their right hand and were told not to move their left hand.

Before entering the magnet, the subjects received $\sim 30 \mathrm{~s}$ of practice to become familiarized with the tracking tasks and sequence of conditions. A blocked design was used to alternate three conditions during the tracking test. The conditions were rest (R), compatible tracking $(\mathrm{C})$, and incompatible tracking (I). These conditions were presented in one of the following sequences of blocks: sequence $1: R_{1}, C_{1}, R_{2}, I_{1}, R_{3}, C_{2}, R_{4}, I_{2}, R_{5}$, $\mathrm{C}_{3}, \mathrm{R}_{6}, \mathrm{I}_{3}, \mathrm{R}_{7}$; sequence 2: $\mathrm{R}_{1}, \mathrm{I}_{1}, \mathrm{R}_{2}, \mathrm{C}_{1}, \mathrm{R}_{3}, \mathrm{I}_{2}, \mathrm{R}_{4}, \mathrm{C}_{2}, \mathrm{R}_{5}, \mathrm{I}_{3}, \mathrm{R}_{6}, \mathrm{C}_{3}, \mathrm{R}_{7}$.

Subjects were randomly assigned to perform only one of these two sequences. Each subject performed early $\left(\mathrm{C}_{1}\right)$, middle $\left(\mathrm{C}_{2}\right)$, and late $\left(\mathrm{C}_{3}\right)$ blocks of the compatible tracking condition as well as early $\left(\mathrm{I}_{1}\right)$, middle $\left(\mathrm{I}_{2}\right)$, and late $\left(\mathrm{I}_{3}\right)$ blocks of the incompatible condition. With each block lasting $30 \mathrm{~s}$ and a 3 s lapse between blocks, the experiment lasted $\sim 7 \mathrm{~min}$. During the rest condition (blocks $\mathrm{R}_{1-7}$ ), the screen displayed a variableamplitude sine wave with the word "rest" appearing at the bottom of the screen. The subjects were instructed to follow the cursor with only their eyes as it moved in a straight line horizontally across the screen. During the compatible condition, the screen displayed a random sine wave with the word "track" appearing at the bottom of the screen. The subjects used flexion and extension of their right index finger to guide the cursor such that upward finger extension guided the cursor upward and downward finger flexion guided the cursor downward. During the incompatible condition, the screen displayed the same target waveform but with the word "reverse" appearing at the bottom of the screen. For the incompatible condition, subjects again used finger flexion and extension to guide the cursor, but now upward finger extension guided the cursor downward, and downward finger flexion guided the cursor upward.

Tracking analysis. Tracking performance was quantified with an accuracy index (AI) (Carey, 1990) defined as follows:

$$
\mathrm{AI}=\frac{100 \times(P-E)}{P},
$$

where $E$ is the root mean square (rms) error between the target line and the response line and $P$ is the magnitude of the subject's target pattern, calculated as the rms difference between the sine wave and the midline separating the upper and lower halves of the target pattern. The maximum possible score is $100 \%$.

Imaging. A high-resolution $\left(1 \mathrm{~mm}^{3}\right), \mathrm{T}_{1}$-weighted, three-dimensional (3D) anatomical image dataset [3D FLASH; repetition time (TR), $20 \mathrm{~ms}$; flip angle (FA), $30^{\circ}$; total acquisition time, $10.44 \mathrm{~min}$ ] was acquired over the entire brain to identify appropriate landmarks and serve as a template on which functional images would be overlaid. $\mathrm{T}_{2}$-weighted fMRIs of the blood oxygen level-dependent (BOLD) signal were taken in the transverse plane with a gradient echo echo-planar imaging sequence (echo time, $30 \mathrm{~ms}$; TR, $3000 \mathrm{~ms}$; FA, $80^{\circ}$; field of view, $192 \times 192 \mathrm{~mm}$ with a matrix size of $64 \times 64$ leading to a resolution of $3 \times 3 \times 3 \mathrm{~mm}$ ). Scans were taken every $3 \mathrm{~s}$ during the $7 \mathrm{~min}$ tracking test. A total of 160 scans were taken, and each slice was $3 \mathrm{~mm}$ thick.

Statistical analysis of the imaging data. Brain Voyager (Brain Innovation, Maastricht, The Netherlands) software was used for fMRI data preprocessing and analysis. The functional bidimensional images of every subject were preprocessed to correct for motion artifacts (movements
$<3 \mathrm{~mm}$ in any plane), for differences in slice scan-time acquisition, and to remove temporal linear trends. In addition to linear detrending, a high-pass filter of three cycles per time course (frequency domain) was applied. These functional images were then used to reconstruct the $3 \mathrm{D}$ functional volume for every subject and every run. The 3D functional volume was aligned with the corresponding 3D anatomical volume, and both were normalized to standard Talairach space (Talairach and Tournoux, 1988). Spatial smoothing using a Gaussian kernel at $8 \mathrm{~mm}$ fullwidth at half maximum was applied to the $3 \mathrm{D}$ functional data. A general linear model (GLM) having six predictors corresponding to the six blocks of activity (three for the compatible and three for the incompatible condition) and a dependent variable, the BOLD signal, expressed as a percentage in relation to the baseline (rest condition), was fitted for each subject and each voxel. The parameters of this GLM model were subsequently entered into a second level of analysis corresponding to a random-effect GLM model that was used for group analysis (Penny and Holmes, 2003). Although the above-mentioned GLM model was fit for each voxel in the entire brain and we did not use any mask, we focused our analysis mainly on regions activated in the DLPFC and ACC. Statistical parametric maps were created for preplanned contrasts, and clusters of activation were displayed only when they contained $\geq 100$ contiguous voxels, the $t$ values of which were $\geq 3.90$ corresponding to a $p$ value of $<0.001$ (uncorrected).

Given the novelty of the task, one would expect that regions involved in implementing movement control should be more active in the early stage of the experiment (i.e., block 1) (Karni et al., 1998) and also more active in the less intuitive condition (i.e., incompatible) (Botvinick et al., 1999; Braver et al., 2001). Therefore, we focused on the following contrasts of interest: early versus late blocks, separately for each condition $\left(\mathrm{C}_{1}\right.$ vs $\mathrm{C}_{3}$ and $\mathrm{I}_{1}$ vs $\left.\mathrm{I}_{3}\right)$; and incompatible versus compatible, in early and late blocks $\left(\mathrm{I}_{1}\right.$ vs $\mathrm{C}_{1}$ and $\mathrm{I}_{3}$ vs $\left.\mathrm{C}_{3}\right)$.

In addition, to explore for possible effects coupled to learning in the more demanding condition (incompatible blocks), we divided the subjects, post hoc, into two halves on the basis of median: the top 10 subjects showed the greatest gain in tracking performance during the incompatible condition from periods 1 to 3 ("high improvers"), and the bottom 10 subjects showed the least gain ("low improvers"). We then ran the same contrasts described above for each of these two groups.

\section{Results}

\section{Behavioral results}

The AI scores for all subjects across the early, middle, and late blocks combined were $75.4 \pm 1.4 \%$ (mean and SEM) for the compatible condition and $67.8 \pm 2.21 \%$ for the incompatible condition. Given that the AI scores were normally distributed, we used parametric tests in the analysis of the behavioral results. Subjects' performances in the compatible condition were significantly better than in the incompatible condition $\left(t_{(19)}=2.963\right.$; $p=0.007)$. However, we were interested in testing whether the performance in the two conditions changed significantly from the early $\left(\mathrm{C}_{1}, \mathrm{I}_{1}\right)$ to the late $\left(\mathrm{C}_{3}, \mathrm{I}_{3}\right)$ part of the experiment, an indicator that task was mastered and that motor control was implemented. Figure 1 shows the behavioral results, for all subjects, in early and late blocks and for compatible and incompatible conditions.

A repeated-measures ANOVA model with block (early vs late) and condition (compatible vs incompatible) as repeated factors was used to analyze the data. The ANOVA showed that subjects' performances were better in the late than early block $\left(F_{(1,19)}=\right.$ 20.649; $p<0.001)$, and it was better overall for the compatible than incompatible condition $\left(F_{(1,19)}=17.043 ; p=0.001\right)$ (Fig. $1)$. In addition, there was a significant interaction effect between the block and condition $\left(F_{(1,19)}=17.081 ; p=0.001\right)$. Sidak tests (Sidak, 1967) adjusting for multiple comparisons showed that the interaction effect is based on a significant change in performance for the incompatible condition, from the early to late block, 


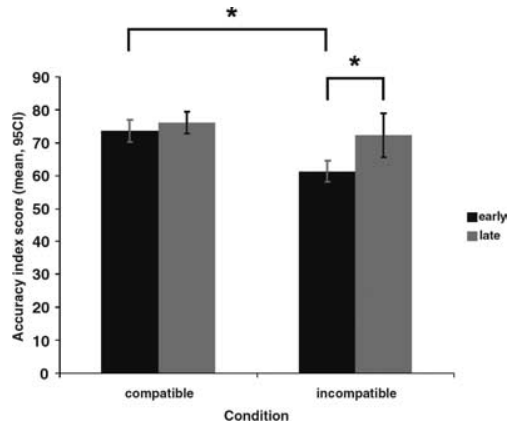

Figure 1. The behavioral performance of all subjects in early and late blocks during compatible and incompatible conditions. Subjects' performances improved significantly for the incompatible condition, from early to late blocks; also, in the early blocks, performance during the compatible condition was better than that during the incompatible condition. Asterisks indicate significant differences between blocks ( $p<0.05$ ). 95Cl, 95\% confidence interval.

whereas such a significant change was not observed for the compatible condition.

\section{Imaging results}

Given the behavioral results, one would expect that regions involved in implementing movement control should be more active in the early stage of the experiment (i.e., block 1) and also more active in the less intuitive condition (i.e., incompatible). Therefore, we ran a contrast in all subjects examining for greater BOLD signal in the early incompatible condition $\left(\mathrm{I}_{1}\right)$ compared with the early compatible condition $\left(\mathrm{C}_{1}\right)$. The $\mathrm{I}_{1}>\mathrm{C}_{1}$ contrast revealed two prefrontal regions, one in the right inferior prefrontal gyrus [Brodmann's area 45 (BA45); 717 voxels; Talairach coordinates: $+39,+19,+20$; maximum $t$ value, 4.99] and another one in the right middle frontal gyrus (BA9; 315 voxels; Talairach coordinates: $+22,+32,+38$; maximum $t$ value, 4.88). Figure 2 shows the localization of these regions in sagittal and transverse planes. In addition to these areas, the only other area showing activation in these contrasts was the right middle temporal gyrus (BA21; Talairach coordinates: $+51,-19,-7$ ).

Next, we looked at changes over time from the first to the third blocks to detect learning/adaptation in each condition separately $\left(\mathrm{I}_{1}>\mathrm{I}_{3}\right.$ and $\left.\mathrm{C}_{1}>\mathrm{C}_{3}\right)$. The contrast $\mathrm{C}_{1}>\mathrm{C}_{3}$ did not reveal any differential activation to surpass our statistical threshold. For the incompatible condition, $\mathrm{I}_{1}>\mathrm{I}_{3}$, activation was revealed in two prefrontal regions, one in the right medial prefrontal gyrus (BA9; 126 voxels; Talairach coordinates: $+13,+50,+30$; maximum $t$ value, 4.81$)$ and another one in the right middle frontal gyrus (BA9; 547 voxels; Talairach coordinates: $+20,+32,+41$; maximum $t$ value, 5.51). The second prefrontal area revealed by this contrast is the same as one of the areas revealed by the previous contrast. In addition, one region in the ACC gyrus was activated by this contrast (BA24; 230 voxels; Talairach coordinates: $0,+17$, +23 ; maximum $t$ value, 4.61) (Fig. 3). This imaging result is consistent with its behavioral counterpart, in which there was a difference in performance from early to late blocks only for the incompatible condition.

To tie the imaging results with the behavioral performance, we decided to examine the correlation between the change in ACC BOLD signal and the change in tracking accuracy between early and late blocks in all subjects for both conditions. We chose the difference scores in this analysis because the imaging results are expressed as a difference (contrast between one condition and another), on one hand, and because we found a significant difference, behaviorally, between early and late incompatible blocks,
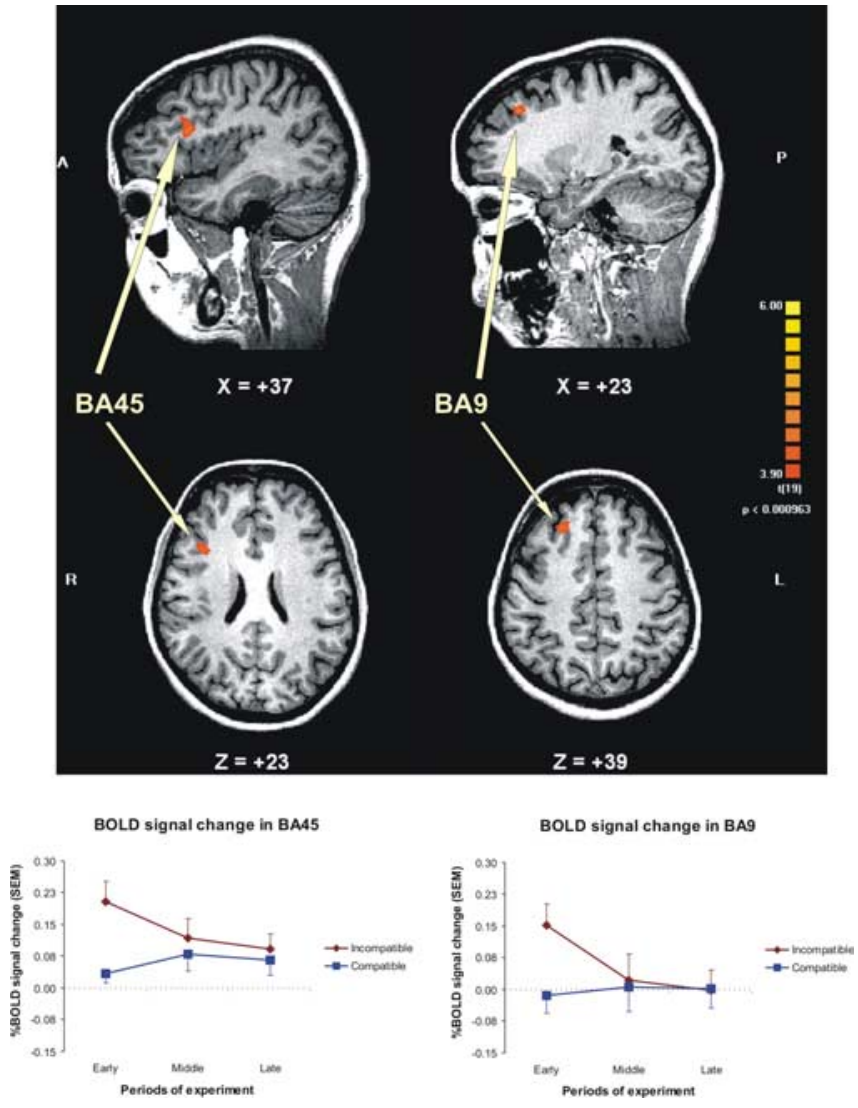

Figure 2. Top, The contrast between early incompatible and compatible conditions $\left(\mathrm{I}_{1}>\right.$ $C_{1}$ ) reveals prefrontal regions (areas $B A 9$ and BA45) involved in movement control implementation. A, Anterior; P, posterior; R, right; L, left. Bottom, The graphs show the BOLD signal for each region and each condition in all blocks of the experiment. Error bars indicate SEM. The arrows point to the same activated cluster in different planes.

on the other hand. As a result of this analysis, we found a significant correlation between ACC difference in activation and change in behavioral performance only for the incompatible $(r=$ $-0.562 ; p<0.01 ; n=20)$ but not for the compatible $(r=0.215$; $p=0.36 ; n=20)$ condition (Fig. 4).

Another way to confirm that activity in these regions (prefrontal and ACC) indeed subserves movement control is to group the subjects based on their improvement in performance across early and late incompatible blocks and examine the activation within each group (e.g., high vs low improvers). To do this, we computed the difference in accuracy between early and late incompatible blocks and split the subjects into two equal groups based on the median of this behavioral variable. Next, we repeated this procedure for the compatible blocks. The analysis of the behavioral results (Fig. 5, top) was performed separately for each group using a GLM model with block (early vs late) and condition (incompatible vs compatible) as independent factors and accuracy as the dependent variable. This analysis showed that subjects in the low improvers group did not change their performance as a function of block $\left[F_{(1,36)}=1.02 ; p=0.31\right.$; mean square error (MSE), 40.29], condition $\left(F_{(1,36)}=2.58 ; p=0.11\right.$; MSE, 40.29), or a combination of the two $\left(F_{(1,36)}=0.78 ; p=\right.$ 0.38 ; MSE, 40.29). In contrast, behavioral performance of subjects in the high improvers group did depend on block $\left(F_{(1,36)}=\right.$ $13.09 ; p<0.001$; MSE, 100.45), condition $\left(F_{(1,36)}=16.72 ; p<\right.$ 0.001 ; MSE, 100.45), and their interaction $\left(F_{(1,36)}=4.64 ; p<\right.$ 0.04; MSE, 100.45). Specifically, these participants were worse 


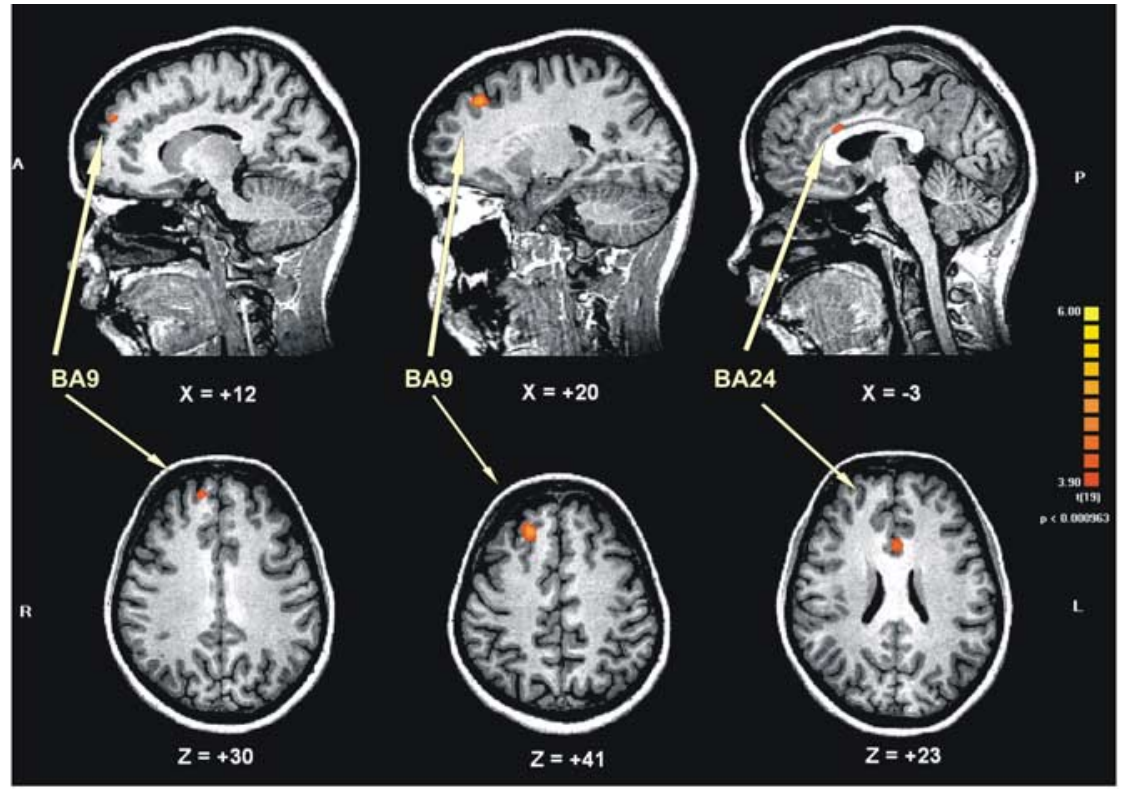

BOLD signal change in BAS
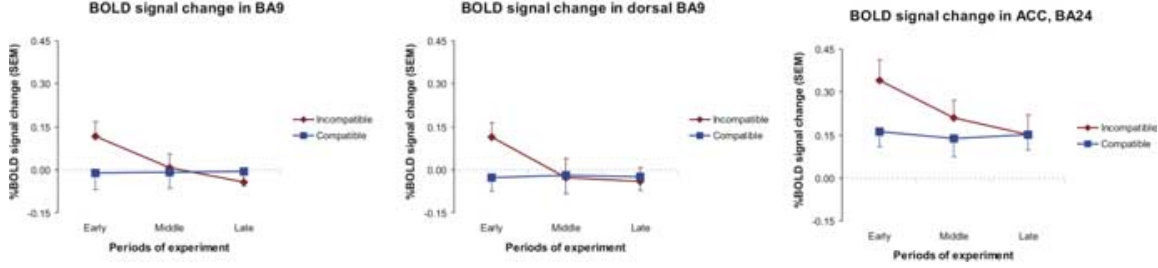

Figure 3. The areas activated by the contrast between early and late incompatible blocks $\left(I_{1}>I_{3}\right)$ in which subjects show significant activation in the PFC and ACC. The corresponding contrast for compatible blocks $\left(C_{1}>C_{3}\right)$ showed no significant activation using the same statistical threshold. Error bars indicate $S E M$. The arrows point to the same activated cluster in different planes. A, Anterior; P, posterior; R, right; L, left.
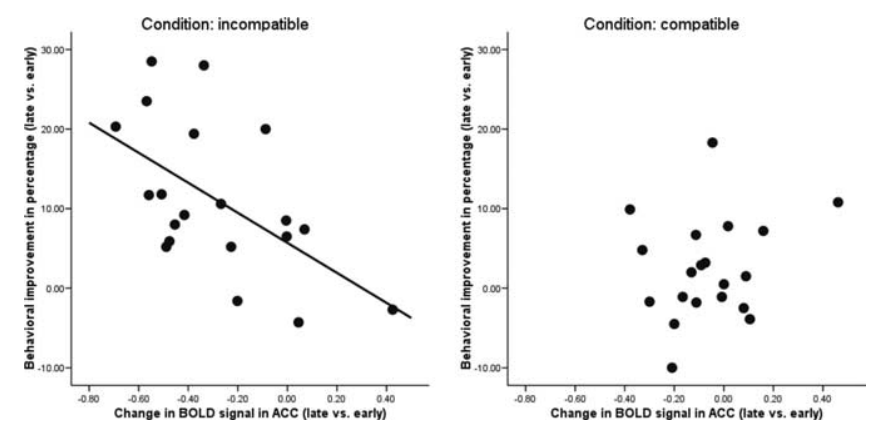

Figure 4. The change in BOLD signal from early to late incompatible blocks in the ACC correlated significantly (negatively) with behavioral improvements observed during the same blocks (incompatible condition; left graph) but not during compatible condition (right graph).

during the incompatible than during the compatible condition in the early blocks of the experiment, but they performed equally well in these conditions in the later blocks. As for the corresponding imaging results, when we ran the contrasts between early incompatible and compatible conditions or between early and late incompatible blocks again, we observed activation in the prefrontal cortex (PFC) and ACC only in the high improvers group. Activity in the PFC reflected the difference in performance between early incompatible and compatible blocks, whereas the activity in the ACC reflected the adaptation to the incompatible condition over time (Fig. 5, bottom). We mention here that given the reduced sample size for these analyses $(n=10)$, we increased our cutoff $t$ value to $t_{\min }=4.80$ to have the same statistical thresh- old as that used in previous analysis for the entire group of subjects ( $p<0.001$, uncorrected). The minimum cluster size was, again, 100 contiguous voxels.

Given that subjects' performances in the incompatible condition improved from block 1 to block 3, we explored for a corresponding shift in neural substrate with a contrast examining for greater BOLD signal in block 3 compared with block $1\left(\mathrm{I}_{3}>\mathrm{I}_{1}\right)$ in all subjects. Four clusters were thus identified: two in the basal ganglia (bilateral caudate nucleus), one in the medial PFC (BA10; 152 voxels; Talairach coordinates: $+19,+65,+20)$, and one in the middle occipital gyrus (BA19; 377 voxels; Talairach coordinates: -41 , $-78,-4)$. Of these clusters, only the difference in activation in the left caudate (364 voxels; Talairach coordinates: -12 , +18 , +1) correlated significantly and negatively with that of the prefrontal region found in the opposite contrast, $\mathrm{I}_{1}>$ $\mathrm{I}_{3}$ (BA9; Talairach coordinates: $+20,+32$, $+41)$. This correlation was significant in the incompatible condition $(r=-0.530$; $p<0.02 ; n=20)$ but not the compatible condition $(r=0.387 ; p=<0.09 ; n=20)$ (Fig. 6), indicating a transfer of movement control implementation from cortical to subcortical levels as performance improved. This finding was strengthened by examining this correlation separately within each group (Fig. 6). For the high improvers, the negative correlation was greater and still significant despite the reduced sample size $(r=-0.713 ; p<0.02 ; n=$ $10)$, whereas the correlation was not significant for the low improvers $(r=-0.388 ; p=0.26 ; n=10)$.

\section{Discussion}

The analysis of the behavioral results suggests that the incompatible condition was the more difficult and showed the biggest improvement in performance. Similar to discrete performance tasks (e.g., Stroop), our results show that the control mechanisms for a continuous task are more likely to be triggered and implemented during incompatible conditions resulting in a beneficial effect on performance.

Our imaging data showed that the neural substrate of cognitive control during a continuous task is similar to that found in discrete tasks, namely the ACC and PFC (Carter et al., 2000; MacDonald et al., 2000; Botvinick et al., 2001). Given the continuous nature of the task and the temporal resolution of fMRI acquisition, we could not directly distinguish between the monitoring and the implementation components of cognitive control. Although there are studies suggesting that ACC might be involved in control implementation itself (Posner and Rothbart, 1998; Markela-Lerenc et al., 2004; Roelofs et al., 2006), a large body of evidence in the cognitive control framework indicates that ACC is the monitoring component (Carter et al., 1998, 2000; Garavan et al., 2002; Botvinick et al., 2004; Kerns et al., 2004b; Brown and Braver, 2005), whereas the prefrontal substrate actually implements the task control (Carter et al., 2000; Dove et al., 2000; Kerns et al., 2004a,b; Egner and Hirsch, 2005a,b). In our 
Behavioral results for high and low 'improvers'

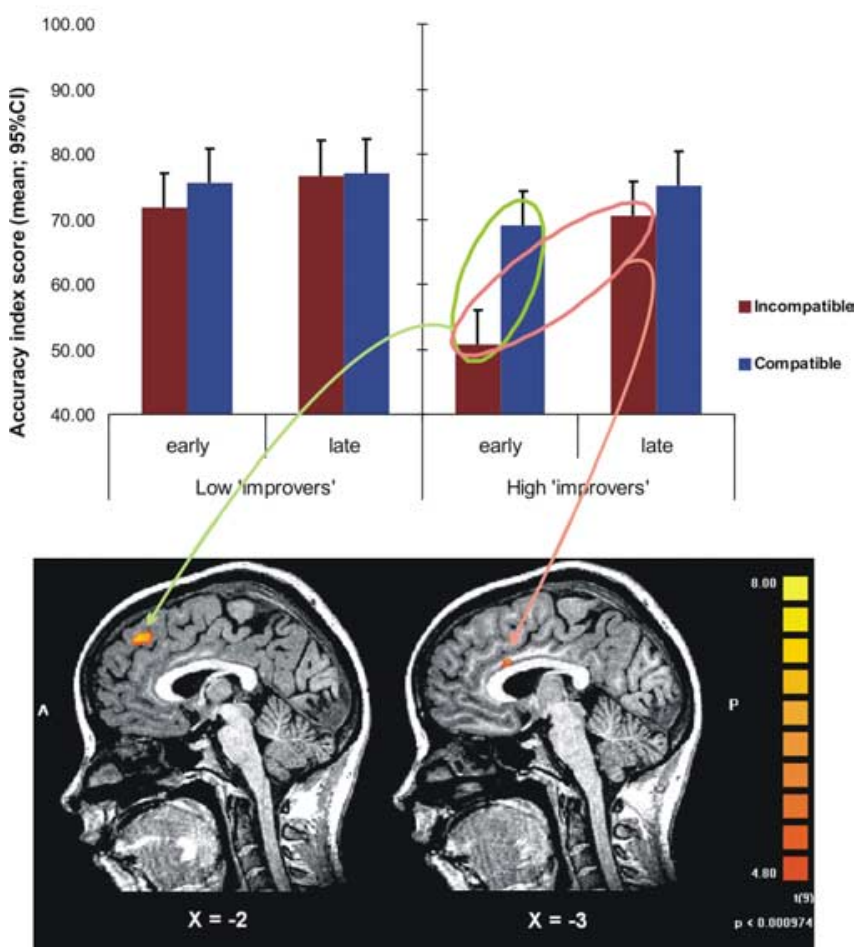

Figure 5. Top, Mean tracking accuracy of high and low improvers during early and late compatible and incompatible blocks. Poor improvers did not change their performance over time or across conditions. High improvers had low performance in the incompatible compared with the compatible condition only early in the experiment, but they improved significantly late in the experiment. Bottom, The regions activated by the contrasts $I_{1}>C_{1}$ (left) and $I_{1}>I_{3}$ (right) in the high-improvers group. No regions were activated by the same contrasts in the lowimprovers group. The arrows point to the same activated cluster in different planes. $95 \% \mathrm{Cl}, 95 \%$ confidence interval; $A$, anterior; $P$, posterior.

study, we found that the PFC was more active in the incompatible versus the compatible condition but only in the early stage of the experiment when the task was less skillful. Furthermore, the PFC was more active in the early stage versus late stage but only for the more difficult incompatible condition. The ACC activity was also more active in the early stage versus late stage of the incompatible condition and, in addition, was correlated negatively with behavioral improvement. This result, interpreted in the conflictmonitoring framework, suggests that as the need to monitor the conflict decreased (i.e., subjects were getting better at the task), so did the activity in the ACC. We point out that given the continuous nature of the task, one cannot differentiate between error rate (deviation from the tracked trajectory) and level of conflict, which were both higher during incompatible blocks. Therefore, the reduction in ACC activity over time may also reflect a response to reduction in error, because previous studies showed that this structure is sensitive to error (Carter et al., 1998; Kiehl et al., 2000) or to predicting the error likelihood (Brown and Braver, 2005).

The imaging analysis performed for the high improvers group revealed a functional specialization of the ACC and PFC (Fig. 5) given that the two contrasts targeted different questions. Contrast $\mathrm{I}_{1}>\mathrm{C}_{1}$ addressed the question of which regions were involved in the initial adaptation to the novel demands of the task (i.e., reverse tracking), whereas contrast $I_{1}>I_{3}$ was designed to show which regions changed their activation over time, as these subjects adapted to these novel demands and mastered the task. We
A.

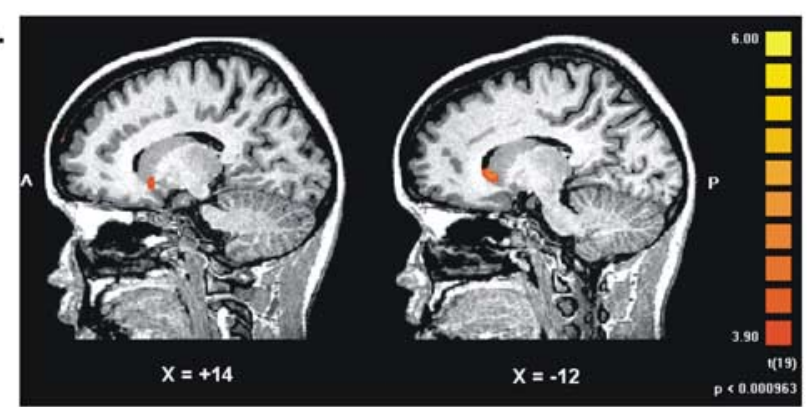

B.
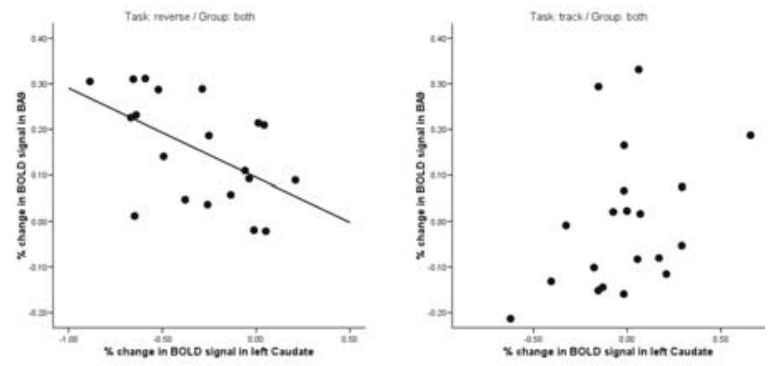

C.
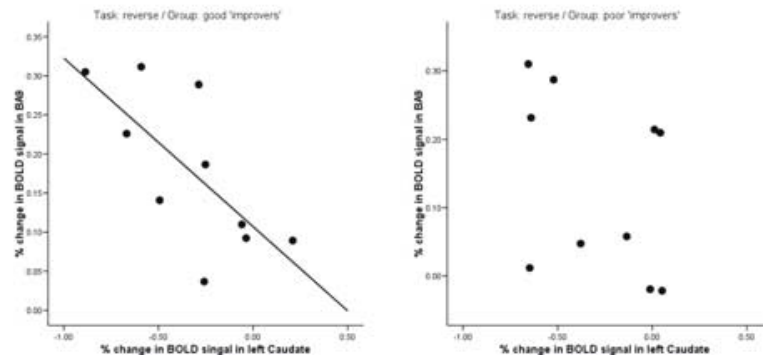

Figure 6. $\quad A$, Two regions in the caudate nucleus, bilaterally, were activated significantly by the contrast $I_{3}>I_{1}$. A, Anterior; $P$, posterior. $B, C$, The activation in the left caudate correlated significantly negatively with the activation in the PFC only during the incompatible but not the compatible condition (B) and only for subjects in the high improvers group (C).

found, for the high improvers group, that the medial PFC seemed to be especially involved in the initial implementation of task control, whereas ACC activity changed over time, as subjects mastered the incompatible condition. Of course, because performance was measured as tracking accuracy, the reduction in ACC activity over time may reflect the reduction in tracking error, given the sensitivity of this region to error (Carter et al., 1998; Kiehl et al., 2000).

Changes in ACC activation over time have previously been shown as a function of task practice (Milham et al., 2003), experiment duration (Erickson et al., 2004), or focus of attention (Mars et al., 2005). However they were either unrelated to the behavioral index measuring conflict (Milham et al., 2003; Erickson et al., 2004) or they were related to attentional shifts regarding the source of error information (Mars et al., 2005). These findings suggest that there could be changes in the neural activity without corresponding changes in behavioral measures, thus questioning the role of the ACC in conflict monitoring and subsequent control implementation. In our study, however, changes in tracking performance in the incompatible condition correlated with changes in ACC activation in support of the conflictmonitoring theory. There are several issues that may explain the difference between our results and these studies. First, there is a difference in the nature of the tasks, discrete versus continuous. Second, we used correlation between pairs of behavioral and imaging measures (score differences) computed for each subject, 
whereas Erickson et al. (2004) used differences in means computed for the entire subject sample. Third, we compared first and last thirds of the time period of the experiment, instead of just first and last halves. If changes are gradual, a comparison between halves may not be as sensitive in revealing significant differences as first and last thirds. Although one cannot exclude the possibility that both behavioral and imaging changes in our results may be produced by additional factors (e.g., changes in focus of attention or a change in strategy used in the task), we consider the correlation between ACC activity and tracking performance as an indication of control implementation.

Notably absent from our imaging results was the activation of posterior parietal regions, which were previously shown to be involved in tracking errors (Krigolson and Holroyd, 2006) or making on-line corrections (Desmurget et al., 1999, 2004a,b) during continuous motor tasks. Given that in these studies the posterior parietal cortex was said to be implicated in a "low-level" type of control, the lack of activation in our case may indicate that subjects used a higher-level type of control based on prefrontal regions. It may be, therefore, that subjects in our study applied a higher-order cognitive rule (e.g., move finger in opposite directions), whereas if cursor deviations were to be at random or as part of a reaching move, a low-level type of control may have been in place, involving the parietal regions and possibly the cerebellum (Doyon et al., 2003). Also, these previous tasks were mostly reaching movements (Desmurget et al., 1999, 2004b) or maintaining a cursor in a region between two moving barriers (Krigolson and Holroyd, 2006). Therefore, the cognitive processes in our task compared with these previous studies may be very different, because the subjects' goals were different. This can also explain the lack of parietal activation in our study.

The other important finding in our experiment expands the cognitive control theory by identifying the neural substrate of the executive component of control in familiar settings (i.e., after a difficult task has been mastered). It is commonly agreed that control implementation, being a resource-consuming endeavor, is not exerted continuously, nor is it exerted in simple tasks. Rather, it is exerted in extraordinary situations (i.e., in novel or difficult tasks) (Miller and Cohen, 2001; Botvinick et al., 2004). However, people accommodate and usually learn difficult tasks or adapt to new situations, reflecting a better implementation of control. For instance, as learning to drive a car progresses and control is better exerted, the driver can effortlessly perform concurrent tasks while driving (e.g., maintaining a conversation). We showed in our experiment that once the more difficult task (incompatible condition) was mastered by the initially less-skillful subjects, the control implementation was transferred from prefrontal to subcortical regions, specifically to the basal ganglia. The activity in the left caudate nucleus displayed the opposite pattern as that in the PFC, and it correlated negatively with the PFC during the incompatible condition. The fact that this correlation was significant only for the subjects who improved the most (high improvers), and only for the incompatible condition, strengthens the argument that the caudate nucleus is the locus of control implementation once a task is well performed. We must emphasize here that the low improvers, who actually did not need additional control in the task because they managed to perform better from the beginning, did not show a difference in caudate activation from early to late periods. This does not mean that they did not use the caudate in their control implementation of the task but rather that this region was not differentially activated across time.

In addition to the basal ganglia, we found more activation in the medial frontal (BA10) and middle occipital (BA19) gyri as the incompatible tracking task was mastered. We believe that this frontal activation may be indicative of prospective memory functions that help subjects anticipate the correct position of the cursor, given their current movement (Adam et al., 2003; Okuda et al., 2006), whereas the occipital activation may subserve selective attention and increase efficiency of visuomotor transformations (Frutiger et al., 2000; Bundesen et al., 2002; Brown et al., 2004).

Our results suggest that although there is a single locus for monitoring the need for control (ACC), there may be multiple loci involved in control implementation, the executive component of the control mechanism. It is conceivable that the need for control should be restricted to a single region, to avoid possible confusion when it comes to estimate the necessity for control recruitment. Not only was the same locus in the rostral ACC (BA24, BA32) consistently found to be involved in control monitoring (Botvinick et al., 1999, 2004; Carter et al., 2000; Kerns et al., 2004b), but it was also found to be processing a variety of modulatory signals, such as errors (Kiehl et al., 2000; Braver et al., 2001; Garavan et al., 2003; Magno et al., 2006), level of conflict (Botvinick et al., 1999; Garavan et al., 2003; Milham and Banich, 2005), and action consequences (Ridderinkhof et al., 2004; Rushworth et al., 2004). In contrast, the executive component of control was not always restricted to the same locus within the PFC, even when the locus of evaluative component in the ACC was similar (Carter et al., 2000; Kerns et al., 2004b). This is consistent with the neural inhomogeneity of the PFC and with its variety of functions (Miller and Cohen, 2001; Koechlin et al., 2003; Ridderinkhof et al., 2004). Having one locus monitoring the need for control and multiple loci responsible for control implementation underlie the flexibility and plasticity of control mechanisms.

Recent studies on patient populations suggest that error processing is primarily dependent on intact connectivity between frontal and striatal circuits (Hogan et al., 2006; Ullsperger and von Cramon, 2006). Although we did not investigate the connectivity between our regions of interest, the correlation between prefrontal regions and the caudate nucleus may be indicative of such circuitry subserving cognitive control in our task. Our results show, in addition, that these frontostriatal circuits may have different functions depending on the learning stage, with frontal areas playing a bigger role in the beginning and the striatum taking the lead once enough experience is acquired in the motor task. Perhaps cognitive control should be viewed from a learning perspective: every novel or difficult task elicits adaptation and, ultimately, learning. Our results regarding the role of the caudate in cognitive control, once the task was mastered, are consistent with a large body of evidence suggesting that corticostriatal circuits underlie motor learning, especially during the late, slow learning phase, when motor skills became automatic (Doyon et al., 2003; Doyon and Benali, 2005; Lehericy et al., 2005).

Having identified that the caudate, in particular, becomes active with such an incompatible behavioral task, a logical next question is whether repeated tracking training in the incompatible and other cognitively challenging tasks could forestall the progression of degenerative diseases affecting the caudate and other basal ganglia.

\section{References}

Adam JJ, Backes W, Rijcken J, Hofman P, Kuipers H, Jolles J (2003) Rapid visuomotor preparation in the human brain: a functional MRI study. Brain Res Cogn Brain Res 16:1-10.

Barch DM, Braver TS, Sabb FW, Noll DC (2000) Anterior cingulate and the monitoring of response conflict: evidence from an fMRI study of overt verb generation. J Cogn Neurosci 12:298-309. 
Botvinick M, Nystrom LE, Fissell K, Carter CS, Cohen JD (1999) Conflict monitoring versus selection-for-action in anterior cingulate cortex. Nature 402:179-181.

Botvinick MM, Braver TS, Barch DM, Carter CS, Cohen JD (2001) Conflict monitoring and cognitive control. Psychol Rev 108:624-652.

Botvinick MM, Cohen JD, Carter CS (2004) Conflict monitoring and anterior cingulate cortex: an update. Trends Cogn Sci 8:539-546.

Braver TS, Barch DM, Gray JR, Molfese DL, Snyder A (2001) Anterior cingulate cortex and response conflict: effects of frequency, inhibition and errors. Cereb Cortex 11:825-836.

Brown GG, Caligiuri M, Meloy MJ, Eberson SC, Kindermann SS, Frank LR, Eyler Zorrilla LT, Lohr JB (2004) Functional brain asymmetries during visuomotor tracking. J Clin Exp Neuropsychol 26:356-368.

Brown JW, Braver TS (2005) Learned predictions of error likelihood in the anterior cingulate cortex. Science 307:1118-1121.

Bundesen C, Larsen A, Kyllingsbaek S, Paulson OB, Law I (2002) Attentional effects in the visual pathways: a whole-brain PET study. Exp Brain Res 147:394-406.

Carey JR (1990) Manual stretch: effect on finger movement control and force control in stroke subjects with spastic extrinsic finger flexor muscles. Arch Phys Med Rehabil 71:888-894.

Carter CS, Braver TS, Barch DM, Botvinick MM, Noll D, Cohen JD (1998) Anterior cingulate cortex, error detection, and the online monitoring of performance. Science 280:747-749.

Carter CS, Macdonald AM, Botvinick M, Ross LL, Stenger VA, Noll D, Cohen JD (2000) Parsing executive processes: strategic vs. evaluative functions of the anterior cingulate cortex. Proc Natl Acad Sci USA 97:1944-1948.

Desmurget M, Epstein CM, Turner RS, Prablanc C, Alexander GE, Grafton ST (1999) Role of the posterior parietal cortex in updating reaching movements to a visual target. Nat Neurosci 2:563-567.

Desmurget M, Grafton ST, Vindras P, Grea H, Turner RS (2004a) The basal ganglia network mediates the planning of movement amplitude. Eur J Neurosci 19:2871-2880.

Desmurget M, Gaveau V, Vindras P, Turner RS, Broussolle E, Thobois S (2004b) On-line motor control in patients with Parkinson's disease. Brain 127:1755-1773.

Dove A, Pollmann S, Schubert T, Wiggins CJ, von Cramon DY (2000) Prefrontal cortex activation in task switching: an event-related fMRI study. Brain Res Cogn Brain Res 9:103-109.

Doyon J, Benali H (2005) Reorganization and plasticity in the adult brain during learning of motor skills. Curr Opin Neurobiol 15:161-167.

Doyon J, Penhune V, Ungerleider LG (2003) Distinct contribution of the cortico-striatal and cortico-cerebellar systems to motor skill learning. Neuropsychologia 41:252-262.

Egner T, Hirsch J (2005a) The neural correlates and functional integration of cognitive control in a Stroop task. NeuroImage 24:539-547.

Egner T, Hirsch J (2005b) Cognitive control mechanisms resolve conflict through cortical amplification of task-relevant information. Nat Neurosci 8:1784-1790.

Erickson KI, Milham MP, Colcombe SJ, Kramer AF, Banich MT, Webb A, Cohen NJ (2004) Behavioral conflict, anterior cingulate cortex, and experiment duration: implications of diverging data. Hum Brain Mapp 21:98-107.

Frith CD, Friston K, Liddle PF, Frackowiak RS (1991) Willed action and the prefrontal cortex in man: a study with PET. Proc Biol Sci 244:241-246.

Frutiger SA, Strother SC, Anderson JR, Sidtis JJ, Arnold JB, Rottenberg DA (2000) Multivariate predictive relationship between kinematic and functional activation patterns in a PET study of visuomotor learning. NeuroImage 12:515-527.

Garavan H, Ross TJ, Murphy K, Roche RA, Stein EA (2002) Dissociable executive functions in the dynamic control of behavior: inhibition, error detection, and correction. NeuroImage 17:1820-1829.

Garavan H, Ross TJ, Kaufman J, Stein EA (2003) A midline dissociation between error-processing and response-conflict monitoring. NeuroImage 20:1132-1139.

Hogan AM, Vargha-Khadem F, Saunders DE, Kirkham FJ, Baldeweg T (2006) Impact of frontal white matter lesions on performance monitoring: ERP evidence for cortical disconnection. Brain 129:2177-2188.

Karni A, Meyer G, Rey-Hipolito C, Jezzard P, Adams MM, Turner R, Ungerleider LG (1998) The acquisition of skilled motor performance: fast and slow experience-driven changes in primary motor cortex. Proc Natl Acad Sci USA 95:861-868.
Kerns JG, Cohen JD, Stenger VA, Carter CS (2004a) Prefrontal cortex guides context-appropriate responding during language production. Neuron 43:283-291.

Kerns JG, Cohen JD, MacDonald III AW, Cho RY, Stenger VA, Carter CS (2004b) Anterior cingulate conflict monitoring and adjustments in control. Science 303:1023-1026.

Kiehl KA, Liddle PF, Hopfinger JB (2000) Error processing and the rostral anterior cingulate: an event-related fMRI study. Psychophysiology $37: 216-223$.

Koechlin E, Ody C, Kouneiher F (2003) The architecture of cognitive control in the human prefrontal cortex. Science 302:1181-1185.

Krigolson OE, Holroyd CB (2006) Evidence for hierarchical error processing in the human brain. Neuroscience 137:13-17.

Lee TD, Genovese ED (1989) Distribution of practice in motor skill acquisition: different effects for discrete and continuous tasks. Res Q Exerc Sport 60:59-65.

Lehericy S, Benali H, Van de Moortele PF, Pelegrini-Issac M, Waechter T, Ugurbil K, Doyon J (2005) Distinct basal ganglia territories are engaged in early and advanced motor sequence learning. Proc Natl Acad Sci USA 102:12566-12571.

MacDonald III AW, Cohen JD, Stenger VA, Carter CS (2000) Dissociating the role of the dorsolateral prefrontal and anterior cingulate cortex in cognitive control. Science 288:1835-1838.

Magno E, Foxe JJ, Molholm S, Robertson IH, Garavan H (2006) The anterior cingulate and error avoidance. J Neurosci 26:4769-4773.

Markela-Lerenc J, Ille N, Kaiser S, Fiedler P, Mundt C, Weisbrod M (2004) Prefrontal-cingulate activation during executive control: which comes first? Brain Res Cogn Brain Res 18:278-287.

Mars RB, Coles MG, Grol MJ, Holroyd CB, Nieuwenhuis S, Hulstijn W, Toni I (2005) Neural dynamics of error processing in medial frontal cortex. NeuroImage 28:1007-1013.

Menon V, Adleman NE, White CD, Glover GH, Reiss AL (2001) Errorrelated brain activation during a Go/NoGo response inhibition task. Hum Brain Mapp 12:131-143.

Milham MP, Banich MT (2005) Anterior cingulate cortex: an fMRI analysis of conflict specificity and functional differentiation. Hum Brain Mapp 25:328-335.

Milham MP, Banich MT, Claus ED, Cohen NJ (2003) Practice-related effects demonstrate complementary roles of anterior cingulate and prefrontal cortices in attentional control. NeuroImage 18:483-493.

Miller EK, Cohen JD (2001) An integrative theory of prefrontal cortex function. Annu Rev Neurosci 24:167-202.

Okuda J, Fujii T, Ohtake H, Tsukiura T, Yamadori A, Frith CD, Burgess PW (2007) Differential involvement of regions of rostral prefrontal cortex (Brodmann area 10) in time- and event-based prospective memory. Int J Psychophysiol, in press.

Oldfield R (1971) The assessment and analysis of handedness: the Edinburgh inventory. Neuropsychologia 9:97-113.

Penny W, Holmes A (2003) Random-effects analysis. In: Human brain function, Chap 42, Ed 2 (Frackowiak RSJ, Friston KJ, Frith CD, Dolan RJ, Friston KJ, Price CJ, Zeki S, Ashburner J, Penny W, eds), pp 843-850. London: Academic.

Posner MI, Rothbart MK (1998) Attention, self-regulation and consciousness. Philos Trans R Soc Lond B Biol Sci 353:1915-1927.

Ridderinkhof KR, Ullsperger M, Crone EA, Nieuwenhuis S (2004) The role of the medial frontal cortex in cognitive control. Science 306:443-447.

Roelofs A, van Turennout M, Coles MG (2006) Anterior cingulate cortex activity can be independent of response conflict in Stroop-like tasks. Proc Natl Acad Sci USA 103:13884-13889.

Rushworth MF, Walton ME, Kennerley SW, Bannerman DM (2004) Action sets and decisions in the medial frontal cortex. Trends Cogn Sci 8:410-417.

Schmidt RA, Lee TD (1999) Motor control and learning: a behavioral emphasis, Ed 3. Champaign, IL: Human Kinetics.

Sidak Z (1967) Rectangular confidence regions for the means of multivariate normal distributions. J Am Stat Assoc 62:626-633.

Talairach J, Tournoux P (1988) Co-planar stereotoxic atlas of the human brain. New York: Thieme.

Ullsperger M, von Cramon DY (2006) The role of intact frontostriatal circuits in error processing. J Cogn Neurosci 18:651-664. 